\title{
Preparation for high-acuity clinical placement: confidence levels of final-year nursing students
}

This article was published in the following Dove Press journal:

Advances in Medical Education and Practice

29 April 2013

Number of times this article has been viewed

\section{Joanne Porter \\ Julia Morphet \\ Karen Missen \\ Anita Raymond}

School of Nursing and Midwifery, Monash University, Churchill, VIC, Australia
Correspondence: Joanne Porter Northways Road, Churchill,

VIC, 3842, Australia

Tel +6I 35I 226440

Email joanne.porter@monash.edu
Aim: To measure final-year nursing students' preparation for high-acuity placement with emphasis on clinical skill performance confidence.

Background: Self-confidence has been reported as being a key component for effective clinical performance, and confident students are more likely to be more effective nurses. Clinical skill performance is reported to be the most influential source of self-confidence. Student preparation and skill acquisition are therefore important aspects in ensuring students have successful clinical placements, especially in areas of high acuity. Curriculum development should aim to assist students with their theoretical and clinical preparedness for the clinical environment.

Method: A modified pretest/posttest survey design was used to measure the confidence of thirdyear undergraduate nursing students $(n=318)$ for placement into a high-acuity clinical setting. The survey comprised four questions related to clinical placement and prospect of participating in a cardiac arrest scenario, and confidence rating levels of skills related to practice in a high-acuity setting. Content and face validity were established by an expert panel $(\alpha=0.90)$ and reliability was established by the pilot study in 2009. Comparisons were made between confidence levels at the beginning and end of semester.

Results: Student confidence to perform individual clinical skills increased over the semester; however their feelings of preparedness for high-acuity clinical placement decreased over the same time period. Reported confidence levels improved with further exposure to clinical placement.

Conclusion: There may be many external factors that influence students' perceptions of confidence and preparedness for practice. Further research is recommended to identify causes of poor self-confidence in final-year nursing students.

Keywords: high acuity, clinical placement, confidence

\section{Summary}

An evaluation tool was developed for final-year undergraduate nursing students to measure perceived confidence in both clinical skill performance and high-acuity clinical placement. The evaluation tool consisted of three sections which reflected collated data relating to: (1) participant characteristics including previous clinical placement experience; (2) self-reported readiness for clinical placement; and (3) participant confidence with individual clinical skills. Content and face validity was established by an expert panel $(\alpha=0.90)$ and reliability was established by the pilot study in 2009 . Final-year students from two university campuses $(n=318)$ enrolled in a single nursing degree were invited to participate in this study. Further research is recommended to validate the survey internationally. 


\section{Introduction}

Universities have a responsibility to produce nurses who are both competent and confident for practice in the clinical setting. It has been reported that self-confidence underpins clinical competency, ${ }^{1}$ and, on this premise, the authors set about investigating third-year student confidence to perform clinical skills and to work in the high-acuity clinical setting.

Self-confidence has been defined as the belief in one's abilities to accomplish a goal or task ${ }^{2}$ and is crucial to effective performance. ${ }^{1,3-5}$ Self-confidence underpins nurses' competence to carry out care effectively ${ }^{1,3}$ and is an important aspect of learning to be a nurse. ${ }^{6}$ Bandura's social learning theory identifies four sources of selfconfidence: (1) performance accomplishment (performing the behavior); (2) vicarious experience (observing another's performance); (3) verbal persuasion (feedback); and (4) emotional arousal (physiological and affective states). ${ }^{7,8}$ Performance accomplishment, or carrying out the skill, is reported to increase confidence to perform the skill again, and is the focus of this paper.

\section{Background}

A review of the literature was conducted using the following databases: Clinicians' Health Channel, ERIC, CINAHL, and MEDLINE, and the search engine Google. The following search terms were used: "clinical placement," "clinical practice," "high-acuity," "undergraduate," "nursing students," and "confidence." The search was supplemented using citation tracking. Articles written in the English language between the years 1990 and 2013 were included.

Clinical skill performance is reported to be the most influential source of self-confidence..$^{3,9,10}$ To this end, the academic simulation laboratory is heavily utilized to allow students to practice clinical skills in a controlled environment. This setting serves the dual purposes of developing competency prior to practicing in the clinical setting and developing confidence, as skills are practiced in a safe setting where no harm can befall the student or patient. Meechan et al found that preparatory education in the way of integrated skills-based teaching assisted students in acquiring confidence prior to clinical placement. ${ }^{11}$

The clinical practicum is an essential component of the undergraduate program that offers nursing students the opportunity to practice their previously learnt clinical skills, linking theory to practice. However, in contrast to the "safety" of the simulated laboratory environment, learning in the clinical setting creates multiple challenges for students, including lack of control over environmental conditions and the management of real life situations. ${ }^{12,13}$ Student confidence to perform in the clinical setting is affected by many factors including lack of experience, fear of making mistakes, difficult patients, discomfort at being evaluated by educators, demeaning experiences, lack of support by nursing personnel, dealing with emergencies, issues related to death and dying, and concern about harming a patient. ${ }^{12,14-16}$

Self-confidence has been reported as being a key component for effective clinical performance, ${ }^{1,5,17}$ and confident students are more likely to be more effective nurses. ${ }^{3,18}$ This may be explained by the relationship between increased levels of self-confidence and increased motivation to practice the skills they have learned. ${ }^{4}$

An interesting finding in the literature is that student confidence to perform in the clinical setting declines over the 3 years of study in the Bachelor of Nursing. ${ }^{19,20}$ In one study, final-year nursing students expressed feelings of unpreparedness, "the sense of knowing so little, when the professional demands would be so great." ${ }^{18}$ In another study, the students felt insufficiently prepared in clinical skills to effectively participate in clinical practice. ${ }^{15}$

This paper presents the perceptions of third-year nursing students at one university over two campuses, measuring their confidence to perform clinical skills and clinical practice using a pre- and posttest design during their first semester.

\section{Method}

\section{Aim}

The aims of this study were to measure final-year nursing students' confidence for clinical skill performance and confidence for high-acuity clinical placement.

\section{Design}

A modified pretest/posttest design was used to measure thirdyear nursing students' clinical skill performance confidence in preparation for a high-acuity placement and following their placement. High acuity was defined as intensive care, critical care, operating theater, coronary care, and the emergency department. Participants in the study completed two surveys but were not individually identified. The data presents a cohort of final-year students at the commencement of the semester prior to clinical placement and a cohort of students postcompletion of a semester of work and/or clinical placement.

\section{Participants}

A convenience sample comprising final-year nursing students from the School of Nursing and Midwifery across 
two campuses of the same university were invited to participate $(n=318)$. Response rate for the pre-survey was $78 \%(n=247)$ and the response rate for the post-survey was $74 \%(n=236)$.

\section{Instrument development}

The survey was designed by the lead author and an expert panel consisting of academics and clinicians. The survey was divided into three sections, including demographics, readiness for clinical placement, and confidence with individual clinical skills. A mixture of fixed responses and open-ended questions was used throughout the survey. Demographic data consisted of age, gender, qualifications (undergraduate student, personal care attendant, enrolled nurse, or other), and clinical experience to date. Utilizing a 4-point Likert scale in which $1=$ not at all, $2=$ a little bit, $3=$ moderately so, and 4 = very much so, participants were asked four key questions regarding readiness for clinical placement.

Participants were instructed to indicate how they felt about five negative and five positively worded statements, eg, "I feel tense," "I feel excited." The key questions addressed commencing third-year of nursing, going on clinical placement as a third-year student, clinical placement in a high-acuity unit, and being involved in an arrest situation while on clinical placement. The basis, from which each item was developed, came from a variety of psychology testing tools which utilized a five-positive and five-negative worddescription technique to formulate participant responses to a single statement, eg, "I feel happy," "I feel sad."

Assessing participants' confidence with clinical skills, students were asked to rate 14 key statements using a 5-point Likert scale in which $1=$ not at all confident, $2=$ not so confident, 3 = unsure, $4=$ confident, and $5=$ extremely confident. The statements included assessment, analysis, and psychomotor skills all taught in the final year of the undergraduate degree, eg, accurately interpret cardiac rhythm strips and effectively perform a jaw thrust.

Survey validity was established through a review process by an expert panel including clinical teachers $(n=2)$, academics $(n=6)$, two third-year students, and a professor of research. The panel agreed on the survey face validity and the wording of the questions. Reliability was established by piloting of the survey on a sample of thirdyear nursing students $(n=124)$ in 2009. On the basis of the comments received, only minor modifications were made to the wording of some of the questions. It was noted that none of the students who participated in the pilot made additional comments in the space provided; however, the lead researcher thought it was important to provide an opportunity for students to write comments, therefore the comment space remained. The surveys were well received by students in the pilot group, and took approximately 10 minutes to complete. The instrument was reliable (Cronbach's $\alpha=0.80$ ) and had good face and content validity approved by an expert panel of academics and clinical educators.

A small amount of qualitative data was also collected from written responses within the survey. Within the pretest survey, the students could provide a written description of their current concerns and feelings based on their preparation for high-acuity placement during their final year. Within the posttest survey, the students had the opportunity to reflect and describe a critical incident that they had experienced during their undergraduate clinical placement.

\section{Survey distribution/data collection}

The surveys and an explanatory statement were distributed to participants studying in the Bachelor of Nursing and Bachelor of Nursing Practice who were enrolled in the third-year highacuity nursing practice unit. Pretest surveys were distributed in week 1 of the semester, prior to unit content delivery and clinical placement, during a lecture at each campus. The posttest survey was distributed during laboratory time in the final week of semester.

\section{Ethical considerations}

Participation in the study was voluntary and responses were anonymous. Ethical approval was obtained from the University Human Ethics Research Committee (Monash University, Churchill, VIC, Australia).

\section{Data analysis}

Each item response was entered into SPSS (v19; IBM Corporation, Armonk, NY, USA) for analysis. Preliminary analyses were conducted to check the accuracy of the data input, identify missing cases and recode variables as required. Data was then analyzed using frequencies and summary statistics to describe the sample characteristics and participants evaluation of their confidence levels regarding clinical placement and high acuity skills. A series of comparative analyses were conducted to compare pre- and posttest survey responses for each item. Qualitative data from the open-ended questions were thematically analyzed to identify themes. Data was coded and then categorized for common themes. All members of the research team reviewed the qualitative results for consensus. This approach of systematically arranging data in an attempt to search for 
categories or themes is supported in qualitative research analysis. $^{21,22}$

\section{Results}

\section{Sample characteristics}

All participants were studying a single nursing degree at one of two university campuses; however, results are presented as a single cohort. A total of 498 surveys were returned. Fifteen surveys were excluded from the final data set as incomplete, leaving 483 completed surveys $(n=247$ pretest, $\mathrm{n}=236$ posttest). The students had all attended a total of 16 hours of clinical laboratory sessions over an eight week period, and had completed a 3000 word assignment. Half the cohort had attended a 2 -week high-acuity clinical placement mid-study, with the other half due to attend a high-acuity clinical placement after completing study.

\section{Demographic data}

Demographic data, as collected on the pretest survey, showed that $91.5 \%$ of the students were female ( $n=226$ pretest), and the students ranged from 19 to 55 years of age with a mean age of 26 years (standard deviation 8.075). Participants were invited to indicate their previous qualifications and/or experience in health care. More than half the participants $(\mathrm{n}=126,51 \%)$ indicated that their only experience in health was as an undergraduate student. One-third $(n=79,32 \%)$ were qualified as an enrolled nurse, and 16.6\% $(n=41)$ indicated that they were a personal care attendant. As shown in Table 1, the most commonly reported previous clinical placement experiences for students was in aged care $(n=198)$, medical $(n=197)$, and surgical $(n=182)$ units.

Students' confidence to perform clinical skills was measured at the beginning and end of the semester. Students

Table I Students' previous clinical experiences

\begin{tabular}{lll}
\hline $\begin{array}{l}\text { Clinical placement } \\
\text { location }\end{array}$ & $\begin{array}{l}\text { Total per } \\
\text { placement } \\
\text { (n) }\end{array}$ & $\begin{array}{l}\text { Total per } \\
\text { placement } \\
\text { (\%) }\end{array}$ \\
\hline Emergency department & 39 & 15.8 \\
Neurological ward & 26 & 10.5 \\
High-dependency unit & 31 & 12.6 \\
Midwifery & 29 & 11.7 \\
Ambulance service & 7 & 2.8 \\
Aged-care facility & 198 & 80.2 \\
Medical ward & 197 & 79.8 \\
Surgical ward & 182 & 73.7 \\
Cardiothoracic unit & 14 & 5.7 \\
Theater & 65 & 26.3 \\
Coronary care unit & 15 & 6.1 \\
Pediatric ward & 37 & 15.0 \\
\hline
\end{tabular}

reported a 95\% mean difference (confidence interval) of the 14 skills measured (Table 2). There was a statistically significant increase in confidence levels in all items from the pretest to the posttest survey $(P<0.0005$ [two-tailed]). The combined scores for each item comparing pre- and posttest results are shown in Table 2 with the differences in these scores noted.

\section{Student comments}

The qualitative data from the pretest surveys demonstrated students' negative emotions or feelings towards clinical placement in a high-acuity setting. The data indicated that the students at this stage of their studies were experiencing negative emotions surrounding their preparation for clinical practice. The themes identified in this analysis indicate that students lack confidence, feel nervous, anxious, scared, or worried about their clinical placement, eg, "I feel nervous about the expectations and not having enough knowledge or confidence to fulfill them." Another student reported feeling "very nervous ... scared I won't know what to do ..."

Students noted that more clinical exposure would assist them in overcoming some of the negative emotions that they were experiencing and would help to increase confidence levels. This is clearly articulated in a comment provided by one participant: "We need more clinical placements to consolidate skills and gain confidence." This perceived lack of confidence was continued in the post-survey responses, with students confirming that additional clinical practice was required: "I lack confidence, a little anxious but felt challenged," and "it was great I got to scribe, nerve racking ... I need more practice."

\section{Discussion}

This study measured nursing students' confidence in performing individual clinical skills both in the laboratory and the clinical setting. As anticipated by the researchers, students' confidence to perform individual clinical skills increased in the posttest study compared with the pretest values. Throughout the study period, students were continually exposed to lectures, clinical skills laboratories, and tutorials that encompassed the measured clinical skills, so these findings were not unexpected.

In contrast, students noted that their confidence to practice in the clinical setting decreased over the study period. Practice in the clinical setting is an essential component of the nursing curricula, and is a compulsory requirement of national nursing registration in Australia. ${ }^{23}$

The clinical setting allows nursing students to practice learnt skills and consolidate practice in a "real-life" 
Table 2 Student confidence to complete clinical skills

\begin{tabular}{|c|c|c|c|c|c|}
\hline Clinical skill & Pretest & Posttest & Difference & $t$ & $\begin{array}{l}\text { Significance } \\
\text { (2-tailed) }\end{array}$ \\
\hline Calculate, prepare, and administer morphine & 26 & 45.8 & +19.8 & -5.293 & 0.000 \\
\hline $\begin{array}{l}\text { Perform a primary and secondary health } \\
\text { assessment }\end{array}$ & 35.6 & 64.4 & +28.8 & -7.706 & 0.000 \\
\hline Perform a focused respiratory assessment & 25.9 & 43.3 & +17.4 & -4.925 & 0.000 \\
\hline Perform a jaw thrust & 35.4 & 48.8 & +13.4 & -5.334 & 0.000 \\
\hline Measure and insert an oropharyngeal airway & 13.7 & 38.1 & +24.4 & -6.899 & 0.000 \\
\hline Perform cardiac compressions & 51.4 & 74.2 & +22.8 & -5.355 & 0.000 \\
\hline Scribe during an arrest situation & |4. | & 23.7 & +9.6 & -2.866 & 0.005 \\
\hline Administer $\mathrm{O}_{2}$ using a high-flow delivery device & 62 & 73.8 & +11.8 & -3.417 & 0.001 \\
\hline Administer $\mathrm{O}_{2}$ via a bag-and-mask apparatus & 50.6 & 69.9 & +19.3 & -5.250 & 0.000 \\
\hline $\begin{array}{l}\text { Understand precautions related to use of the } \\
\text { defibrillator }\end{array}$ & 23.8 & 44 & +20.2 & -7.554 & 0.000 \\
\hline Define the roles of the arrest team & 14.9 & 37.7 & +22.8 & -6.896 & 0.000 \\
\hline Perform a 12-lead electrocardiogram & 51.8 & 71.2 & +19.4 & -5.452 & 0.000 \\
\hline Identify the equipment required for intubation & 6.9 & 22.9 & +16 & -7.062 & 0.000 \\
\hline Interpret cardiac rhythm strips & 6.5 & 23.3 & +16.8 & -9.051 & 0.000 \\
\hline
\end{tabular}

Note: Pre- and posttest comparison.

environment. Exposure to the multidisciplinary team, complex equipment, and a diverse range of patients results in undergraduate clinical placement being identified as "the core of nursing education." ${ }^{13}$

It is widely recognized that student nurses lack confidence related to their clinical placements ${ }^{24-29}$ and this is reflected in the findings of this study. One factor that is reported to decrease confidence in clinical placement is the way in which nursing students are treated by qualified nursing staff, with reports of bullying and intimidation. . $^{12,30,31}$ This behavior was not evident in the current study. Of the 483 responses, there were no data to indicate that students were mistreated by other nurses or experienced difficulties with preceptors. Instead, the feedback about support during placement was positive, with one participant reporting, "my preceptor was very good, staying by my side and explaining every aspect of what was happening."

An unexpected finding in this study was a reduction in the students' confidence to perform in the clinical setting over the semester. Given the previously described educational program provided to the students, it might be anticipated that students' confidence would increase, yet three previous studies have also found that nursing students' level of self-esteem decreased over the duration of the course. ${ }^{19,32,33}$ Randle $^{33}$ reported that student nurses had average levels of self-confidence on course commencement, but that by completion, $95 \%$ of students perceived themselves as anxious, depressed, and unhappy. Edwards et a ${ }^{19}$ suggest that external factors common to all nursing students can affect the level of reported selfconfidence, suggesting that application for jobs is linked with lower self-confidence and the fear of rejection. This was relevant with this study as the participants completing the posttest survey were in the process of applying for graduate employment, and this may have influenced their reported decreased level of confidence to practice.

Much of the reported data in relation to clinical placement reflected those reported in previous studies. In Beck and Srivastava' ${ }^{34}$ study of first-year nurses' readiness for initial clinical practice, the author found that student nurses "had no self-confidence" and felt they were "not qualified to be there." This was confirmed by subsequent studies in which "harming the patient," "making mistakes," 12 and "feeling unprepared"18 were reported as nursing-student concerns. Each of these themes was reflected in the qualitative data collected in this current study. Students reported feeling "not yet prepared enough;" "as though all the knowledge hasn't come together;" "anxious about the ... responsibility;" and in a "constant state of panic" prior to commencing clinical placement. Students identified that "more clinical placement time" would assist in allaying these fears. This is supported by the confidence data, which revealed that students who had completed the high-acuity clinical placement had higher confidence for practice than students who were yet to complete the clinical placement.

\section{Limitations of the study}

The surveys were not coded for individual students, thus excluding the opportunity to explore reflections and confidence levels in a pretest/posttest design. Students were represented in this article as a single pre-group and a single post-group. Correlation statistics were therefore not 
available between individual survey items, thus limiting the data analysis. However, the authors remained in consensus regarding the study's ability to compare the cohorts with regard to clinical preparation and theoretical knowledge. This study identified a number of psychomotor skills associated with preparation for a high-acuity clinical placement. The authors acknowledge that knowledge, cognitive, and interpersonal skills also contribute to the students learning and to increasing confidence. Further research is recommended to explore these aspects.

\section{Conclusion}

This paper presented findings from a single university; however it will be of interest to curriculum development internationally as growing numbers of nursing students prepare for high-acuity clinical placement. The study concluded that final-year students' confidence to perform individual clinical skills increased over a semester, with statistically significant scores found between the pre- and posttest survey results. Conversely, students' feelings of preparedness for clinical placement decreased over the same time period, although it was noted that this was expected to improve with additional exposure to clinical practice. There may be many external factors that influence students' perceptions of confidence and preparedness for practice. Future studies should include interviews with participants to identify the cause of decreasing confidence, and may also include interventions to help manage self-confidence among final-year nursing students.

\section{Disclosure}

The authors report no conflicts of interest in this work.

\section{References}

1. Crooks D, Carpio B, Brown B, Black M, O’Mara L, Noesgaard C. Development of professional confidence by post diploma baccalaureate nursing students. Nurse Educ Pract. 2005;5(6):360-367.

2. Crisp J, Taylor C, Douglas C, Rebeiro G. Potter and Perry's Fundamentals of Nursing - Australian Version, 4th ed. Sydney: Mosby, Elsevier; 2012.

3. Brown B, O'Mara L, Hunsberger M, et al. Professional confidence in baccalaureate nursing students. Nurse Educ Pract. 2003;3(3):163-170.

4. Farrand P, McMullan M, Jowett R, Humphreys A. Implementing competency recommendations into pre-registration nursing curricula: effects upon levels of confidence in clinical skills. Nurse Educ Today. 2006;26(2):97-103.

5. Mavis B. Self-efficacy and OSCE performance among second year medical students. Adv Health Sci Educ Theory Pract. 2001;6(2):93-102.

6. Calman L. Patients' views of nurses' competence. Nurse Educ Today. 2006;26(8):719-725.

7. Bandura A. Self-efficacy: toward a unifying theory of behavioral change. Psychol Rev. 1977;84(2):191-215.

8. Bandura A. Self-efficacy mechanism in human agency. American Psychologist. 1982;37:122-147.
9. Pike T, O'Donnell V. The impact of clinical simulation on learner self-efficacy in pre-registration nursing education. Nurse Educ Today. 2010;30(5):405-410.

10. Sinclair B, Ferguson K. Integrating simulated teaching/learning strategies in undergraduate nursing education. Int $J$ Nurs Educ Scholarsh. 2009;6:Article 7.

11. Meechan R, Jones H, Valler-Jones T. Students' perspectives on their skills acquisition and confidence. Br J Nurs. 2011;20(7):445-450.

12. Elliott $M$. The clinical environment: a source of stress for undergraduate nurses. Aust J Adv Nurs. 2002;20(1):34-38.

13. Bourgeois S, Drayton N, Brown AM. An innovative model of supportive clinical teaching and learning for undergraduate nursing students: the cluster model. Nurse Educ Pract. 2011;11(2):114-118.

14. Timmins F, Kaliszer M. Aspects of nurse education programmes that frequently cause stress to nursing students - fact finding sample survey. Nurse Educ Today. 2002;22(3):203-211.

15. Sharif F, Masoumi S. A qualitative study of nursing student experiences of clinical practice. BMC Nurs. 2005;4:6.

16. Moscaritolo LM. Interventional strategies to decrease nursing students anxiety in the clinical learning environment. J Nurs Educ. 2009; 48(1):17-23.

17. Chesser-Smyth PA, Long T. Understanding the influences on selfconfidence among first-year undergraduate nursing students in Ireland. J Adv Nurs. 2013;69(1):145-157.

18. Magnussen LA, Amundson MJ. Undergraduate nursing student experience. Nurs Health Sci. 2003;5(4):261-267.

19. Edwards D, Burnard P, Bennett K, Hebden U. A longitudinal study of stress and self-esteem in student nurses. Nurse Educ Today. 2010; 30(1):78-84.

20. Lindop E. Individual stress among nurses in training: why some leave while others stay. Nurse Educ Today. 1991;11(2):110-120.

21. Gillis A, Jackson W, Beiswanger D. University nurse graduates: perspectives on factors of retention and mobility. Nurs Leadersh (Tor Ont). 2004;17(1):97-110.

22. Wood MJ, Roos-Kerr J. Basic steps in Planning Nursing Research: From Question to Proposal, 6th ed: Sudbury, MA: Jones and Bartlett; 2006.

23. Preston B. National Framework for the Accreditation of Nursing and Midwifery Courses Leading to Registration, Enrollment, Endorsement and Authorisation in Australia. Canberra: Australian Nursing and Midwifery Council (ANMC); 2007.

24. Beck CT. Nursing students' initial clinical experience: a phenomenological study. Int J Nurs Stud. 1993;30(6):489-497.

25. Casey K, Fink R, Krugman M, Propst J. The graduate nurse experience. J Nurs Adm. 2004;34(6):303-311.

26. Casey K, Fink R, Jaynes C, Campbell L, Cook P, Wilson V. Readiness for practice: the senior practicum experience. J Nurs Educ. 2011; 50(11):646-652.

27. Duchscher JE. Transition shock: the initial stage of role adaptation for newly graduated registered nurses. J Adv Nurs. 2009;65(5): $1103-1113$.

28. James A, Chapman Y. Preceptors and patients - the power of two: nursing student experiences on their first acute clinical placement. Contemp Nurse. 2009;34(1):34-47.

29. Newton JM, McKenna L. The transitional journey through the graduate year: a focus group study. Int J Nurs Stud. 2007;44(7):1231-1237.

30. Evans W, Kelly B. Pre-registration diploma student nurses stress and coping measures. Nurse Educ Today. 2004;24(6):473-482.

31. Shipton SP. The process of seeking stress-care: coping as experienced by senior baccalaureate nursing students in response to appraised clinical stress. J Nurs Educ. 2002;41(6):243-256.

32. Lees $\mathrm{S}$, Ellis $\mathrm{N}$. The design of a stress-management programme for nursing personnel. J Adv Nurs. 1990;15(8):946-961.

33. Randle J. Changes in self-esteem during a 3-year pre-registration diploma in higher education (nursing) programme. J Clin Nurs. 2003; 12(1):142-143.

34. Beck DS, Srivastava R. Perceived level and source of stress in baccalaureate nursing students. J Nurs Educ. 1991;30(3):127-133. 
Advances in Medical Education and Practice

Dovepress

\section{Publish your work in this journal}

Advances in Medical Education and Practice is an international, peerreviewed, open access journal that aims to present and publish research on Medical Education covering medical, dental, nursing and allied healthcare professional education. The journal covers undergraduate education, postgraduate training and continuing medical education including emerging trends and innovative models linking education, research, and healthcare services. The manuscript management system is completely online and includes a very quick and fair peer-review system. Visit http://www.dovepress.com/testimonials.php to read real quotes from published authors.

Submit your manuscript here: http://www.dovepress.com/advances-in-medical-education-and-practice-journal 